Case Report

\title{
Total Hysterectomy as Treatment for Recurrent Chronic Pyometra in Mares With Total Cervical Adhesion-Case Report
}

\author{
Nereu Carlos Prestes, Felipe Erison Medrado, Lucas Troncarelli Rodrigues, \\ Lucas Emanuel Ferreira Canuto, Jéssica Cristina Lemos Motta, \\ Lorenzo Garrido Segabinazzi*, Marco Antonio Alvarenga
}

Department of Animal Reproduction and Veterinary Radiology, São Paulo State University, UNESP Botucatu, São Paulo, Brazil

\section{A R T I C L E I N F O}

\section{Article history:}

Received 26 November 2017

Received in revised form

4 January 2018

Accepted 12 January 2018

Available online 9 February 2018

\section{Keywords:}

Pyometra

Equine

Fertility rate

Uterine problem

Uterine infection

\begin{abstract}
A B S T R A C T
Radical hysterectomy is indicated as a last resource in pyometra that does not respond to pharmacological therapy, uterine torsion with vascular involvement and onset of necrosis, neoplasia, ruptures of impossible synthesis and rarely, segmental aplasia with accumulation of secretion. The incidence of pyometra is multifactorial, being an unusual condition in this species. Generally, it is originated by failure of the physiological draining of the uterine fluid, which may be due to the presence of cervical adherences or to a sinuous or irregular cervical canal, as well as due to its stenosis. The diagnosis is conducted by a complete gynecological exam, which consists of rectal palpation, ultrasound examination, culture and antibiogram of the content, and can be complemented by uterine biopsy when it is possible. Differential diagnosis should be conducted to confirm the absence of gestation, mucometra and pneumometra. The present report is about an equine female, Mangalarga breed, 23 years old, body weight of $470 \mathrm{~kg}$, diagnosed with recurrent chronic pyometra that was unsolved by conventional methods, and surgical intervention was performed for hysterectomy as a treatment of selected.
\end{abstract}

(C) 2018 Elsevier Inc. All rights reserved.

\section{Introduction}

Hysterectomy represents one of the greatest challenges in terms of surgical access in equine species. This procedure can be total, in pyometra cases, or partial in case of tumors. Hysterectomy is commonly indicated in cases of pyometra that do not respond to conventional therapies. Other indications are uterine torsion with impairment of the organ, neoplasia, ruptures of impossible synthesis, and rarely, segmental aplasia with accumulation of secretion $[1,2]$.

Mild abdominal discomfort is the most evident sign of hysterectomy, presumably related to maneuvers and tension in the ovarian pedicle and broad ligament during the intraoperative

\footnotetext{
Animal welfare/ethical statement: The study was approved by the Ethics and Animal Use Committee, with protocol number 0224/2017, from the São Paulo State University (UNESP), Botucatu campus, SP, Brazil.

Conflict of interest statement: The authors declare no conflicts of interest.

* Corresponding author at: Lorenzo Garrido Segabinazzi, Department of Animal Reproduction and Veterinary Radiology, São Paulo State University, UNESP, Distrito de Rubião Junior, s/n, Brazil.

E-mail address: lgseg@hotmail.com (L.G. Segabinazzi).
}

period. Edema and seroma formation are also expected, and they can be related to the residual space in the subcutaneous [3]. Complications, such as severe hemorrhage, septic peritonitis, necrosis, uterine stump infection, abscess, colitis, and fever, have also been reported [4-6].

The aim of the present report is to describe a case of surgically treated pyometra in a mare, as well as its possible complications and prognosis.

\section{Case Report}

The present report is about an equine female, Mangalarga breed, aged 23 years, body weight of $470 \mathrm{~kg}$, examined at the Animal Reproduction service of Faculty of Veterinary Medicine and Animal Science, Paulista State University, Botucatu, SP. The intervention was the second one performed in 54 years. The mare presented with dystocia 2 years ago, and it was submitted to fetotomy in the veterinary hospital 1 . As a consequence of a neglected puerperium regarding to the sequela from the obstetric procedures, the animal developed severe cervical laceration, with loss of anatomical conformation and total healing of its natural opening, occurring accumulation of lochia that progressed to pyometra. One year later, 
the animal returned to a veterinary hospital (hospital 2), when the obliterating membrane was perforated manually, and the purulent content was drained. A standard intensive treatment was recommended, based on the culture and antibiogram of the material collected. However, the treatment was neglected again, due to a new cicatricial reaction that deformed and obliterated the entire vaginal fornix. Twelve months later, the animal was referred to the Veterinary Hospital of Paulista State University, Botucatu, where it was submitted to a complete gynecological examination. It was diagnosed pyometra of impossible resolution, remaining as a last option for the treatment the hysterectomy with the agreement of the owner, who was properly informed. The preanesthetic and preoperative procedures were performed, and the animal was submitted to laparotomy. It was collected samples of subcutaneous adipose tissue with skin fragment for an eventual cloning in the future. In addition, both ovaries were preserved to allow for the use of biotechnologies in the future to perpetuate the genetic potential of the mare. In the postoperative period, surgical wound care, antibiotic therapy, antiinflammatory-analgesic, and daily physical examination were established. Furthermore, laboratory tests were performed regularly, and their results demonstrated fluctuating values in an 8 days interval. When all the parameters were stabilized, and the stitches were removed, on the 10th day after surgery, the animal had been discharged from the hospital.

\subsection{Diagnostic}

During the gynecological examination by vaginoscopy, it was observed the adherence of the entire vaginal fornix, being impossible to identify and to visualize the cervical rings. Thus, it was not possible to drain the intrauterine content. Rectal palpation showed dilatation of the uterine body and horns; the body had a fluctuant consistence for the presence of fluids. Furthermore, an ultrasound examination using a $5.0 \mathrm{MHz}$ linear transducer (Mindray Dp 2200) was performed, and an increase in the endometrial and mesometrial thickness, as well as the presence of hyperechoic and homogeneous content in the uterine lumen were detected.

\subsection{Treatment}

\subsubsection{Anesthetic Procedure}

In the anesthetic induction room, $0.05 \mathrm{mg} / \mathrm{kg}$ (intramuscular) of $2 \%$ acepromazine was administered. Thirty minutes later, a catheter (14 G catheter) coupled to a three-way stopcock was inserted in the jugular vein. Xylazine was administered intravenously $(0.5 \mathrm{mg} / \mathrm{kg}$; IV), followed by the administration of guaiacol glycerol ether 5 minutes later, which was injected until the animal started to show signals of ataxia. Then, ketamine and diazepam were administrated in the doses of $2.2 \mathrm{mg} / \mathrm{kg}$ and $0.1 \mathrm{mg} / \mathrm{kg}$, respectively. Subsequently, the animal was taken to the surgical center, where it was placed in a dorsal decubitus position on a hydraulic table. The animal was connected to the mechanical ventilator that had been set to 6 breaths per minute, in a tidal volume of $10-15 \mathrm{~mL} / \mathrm{kg}$ to maintain the carbon dioxide gas at the end of the exhalation between 35 and $45 \mathrm{mmHg}$. Anesthesia was maintained using isoflurane, combined to continuous infusion of lidocaine, and bolus of $1.2 \mathrm{mg} / \mathrm{kg}$ IV every 15 minutes, followed by infusion of $3 \mathrm{mg} / \mathrm{kg} / \mathrm{hour}$, which was interrupted 30 minutes before the end of the procedure. Arterial blood pressure was maintained above $60 \mathrm{mmHg}$, and when the pressure declined below this value, dobutamine was administered by continuous infusion.

\subsubsection{Preoperative Procedure}

When the mare reached the anesthesia pattern, it was submitted to a trichotomy from the xiphoid process to the inguinal region. Preantisepsis was performed using chlorhexidine gluconate $2 \%$ and iodine solution $1 \%$ (polyvinylpyrrolidone).

\subsubsection{Intraoperative Procedure}

Antisepsis was carried out with $1 \%$ iodine solution followed by $70 \%$ alcohol. The surgical drape was placed, then the laparotomy was initiated with a preretro-umbilical incision to close to the mammary gland. Exposure of body and uterine horns was performed, and one of the uterine horns was externalized; the purulent content was removed using a vacuum pump. However, it was unsuccessful due to the consistency of the content. Thus, it was decided to incise the organ with the scalpel blade, draining $22 \mathrm{~L}$ of purulent material, which was dense and odorless. After that, the uterine size decreased, and the incision was sutured using a cruciate pattern (Fig. 1). Then, ligatures of the broad ligament vessels and the ovarian pedicle were performed individually, using vicryl 2 . When the hemostasis was completed, the hysterectomy was initiated. A transfixation was performed in the uterine body before its incision, and the parker kerr suture pattern was performed using vicryl 2. Both ovaries were preserved. The abdominal wall was sutured using cruciate pattern interspersed with simple interrupted stitches with vicryl 2 and the skin with vertical mattress pattern with supramid no 3 .

\subsubsection{Postoperative Procedure}

During 5 days of the postoperative period, the wound bandage was performed twice a day, temperature was measured three times a day, daily hemogram was conducted, and sulfamethoxazole + trimethoprim (Trissulfin; $15 \mathrm{mg} / \mathrm{kg}, \mathrm{IV}$, B.I.D.) and flunixin meglumine (Banamine; $1.1 \mathrm{mg} / \mathrm{kg}$, I.V., T.I.D.) was administrated. In addition, the animal was treated with omeprazole ( $4 \mathrm{mg} / \mathrm{kg}$, orally, S.I.D.) until discharge from the hospital. This last treatment was conducted to avoid the occurrence of gastroduodenal ulcers that can occur due to the prolonged administration of nonsteroidal antiinflammatory drugs, as well as, stress conditions caused by the surgery and hospitalization.

\section{Discussion}

Pyometra is defined as the accumulation of mucopurulent material within the uterus [7] with or without corpus luteum, depending on the degree of lesion in the endometrium [8]. When the endometrium is severely damaged, with extensive loss of superficial epithelium, severe endometrial fibrosis, and glandular atrophy, it results in a prolonged luteal phase, due to the reduction of synthesis and release of prostaglandin F2 $\alpha$. In the mild endometritis, which presents accumulation of small amounts of fluid in the uterine lumen, premature release of prostaglandin F2 $\alpha$ occurs and consequently luteolysis. The endometrial histopathology of acyclic mares revealed severe endometrial injury with almost complete erosion and atrophy [8].

The occurrence of pyometra in mares is multifactorial, being an unusual condition in this species. Usually, it is originated by failure of the physiological drainage of the uterine fluid, which may be due to the presence of cervical adhesions or sinuous or irregular cervical canal, as well as due to its stenosis [8-10]. Intrauterine accumulation of purulent material in mares had also been observed in the presence of an open cervix [8,11], probably these animals may have reduced endometrial resistance to infection and can progress to pyometra [12]. A potential cause of insufficient uterine drainage, regardless of cervical competence, can be intraabdominal adhesions, which makes the organ become pendulous [9]. The cervix represents the third and last barrier between the uterus and the external environment in the reproductive tract of the mare [13], 
being a dynamic structure that functions under hormonal control during the estrous cycle [14]. During the calving, also under hormonal influence, the cervix is completely dilated, allowing the foal to pass through [15]. It is fundamental the nonoccurrence of lesions in this structure in the moment of parturition because if its function is compromised, the mare becomes susceptible to infections and may result in infertility [16].

Cervical adhesions are reported as pathological conditions that impair the reproductive capacity of mares and can be transluminal or vaginal [16]. They are usually induced during natural delivery or forced traction or by repeated cervical manipulations that occur during fetotomy, as well as in an iatrogenic manner, during intrauterine treatment, artificial insemination, and embryo transfer, for instance [17].

Because the clinical signs of pyometra are rarely manifested [8], this disease is usually diagnosed through the observation of purulent vulvar secretion $[3,18]$.

The diagnosis of pyometra is performed by a complete gynecological examination, which consists of rectal palpation, ultrasound examination, culture, and antibiogram of the contents and can be complemented by uterine biopsy. Differential diagnosis should be made to confirm the absence of gestation, mucometra, and pneumometra $[9,19]$.

There are some microorganisms that are associated with pyometra in mares, with the most common being the following: Streptococcus equi (subsp. S. zooepidemicus) [8,18], Escherichia coli, Actinomyces sp., Pasteurella sp., Pseudomonas sp., Propionibacterium sp., and Candida rugosa $[8,20]$. In contrast to the above,
Citrobacter diversus was isolated, being resistant to gentamicin, ampicillin, ceftiofur, and amoxicillin clavulanate. It was sensitive to the following: enrofloxacin, norfloxacin, chloramphenicol, sulfamethoxazole + trimethoprim, and partially sensitive to florfenicol.

The treatment of pyometra consists of dilation of the cervix and to remove its adhesions to allow uterine flushing and specific antimicrobial treatment [19]. After this intervention, it is possible to form new adhesions, which can be prevented by maintaining a drain or placing an intrauterine catheter with the cuff inflated [21]. Topical application of antimicrobial and antiinflammatory ointments may be beneficial. Prostaglandin F2 $\alpha$ administration and exogenous oxytocin for luteolysis and stimulation of myometrial contractility can promote the expulsion of the uterine contents because there are no occlusions that block the flow to the external environment [9]. In the present report, performing these procedures was not possible because of the risk of rupture of the vaginal fornix and flow of the contents into the abdominal cavity.

In cases of severe intraluminal cervical adhesions that compromise the functionality of the anatomical structure, pyometra tends to be recurrent, and ovariohysterectomy is indicated as treatment $[2,4]$. This procedure is rare to be performed in mare, and it is considered quite invasive due to the pelvic location of the uterus in this species, with surgical access being a challenge [1,22].

To reduce the occurrence of infections, the drainage of the contents from the uterus must be performed before ovariohysterectomy. However, in most cases of pyometra, the uterus can only be emptied partially before surgery. Thus, it must be externalized and
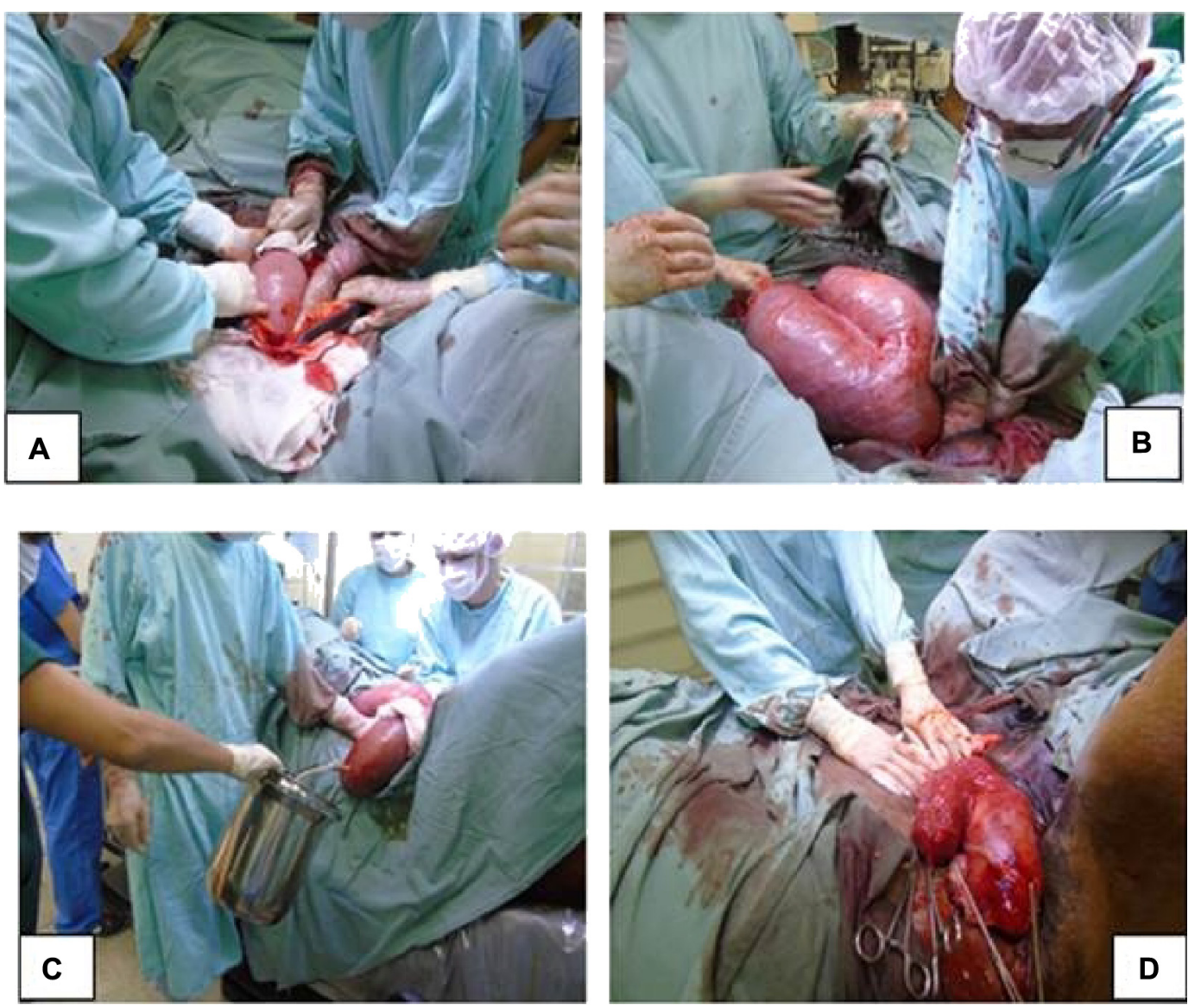

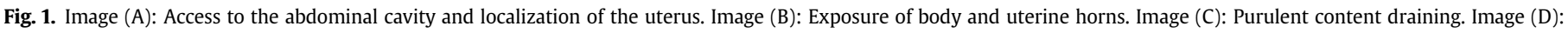
Uterus after drainage procedure. 
the contents drained to avoid abdominal or incisional contamination [3]. In the present case, it was tried first to use a vacuum pump to drain the content without success. Then, it was necessary to incise the organ to reduce its content.

In the present report, only hysterectomy was performed, preserving both ovaries to allow the use of biotechnology in the future to perpetuate the genetic potential of the mare $[2,6]$. The removal of the entire endometrium was suggested before suturing the uterine stump because its presence is related to the occurrence of peritonitis. This procedure was not performed in our case, and no peritonitis was observed.

According to the study by Rötting et al [6], the prognosis after ovariohysterectomy, total or partial hysterectomy is positive, even with all the technical difficulties of the procedure and advanced stages of the disease with incorrect or neglected treatments. Our result is in agreement with this study. In the report from these authors, six total ovariohysterectomies were performed, and they were indicated to treat a chronic pyometra $(\mathrm{n}=4)$ and a uterine torsion $(\mathrm{n}=2)$. In addition, a partial ovariohysterectomy was reported to treat a chronic intramural hematoma. In the same study, the most common postoperative complications were as follows: decreased fecal production, decreased intestinal motility $(n=4)$, and mild abdominal pain $(\mathrm{n}=2)$. Two mares had mild to moderate incisive infections. Other complications reported in previous studies [4], such as hemorrhage, septic peritonitis, uterine stump infection or necrosis, and diarrhea did not occur. All mares survived and were used later for equitation $(n=6)$ and embryo transfer ( $\mathrm{n}=1$, after partial ovariohysterectomy).

Our observations during the postoperative period were contrasting those mentioned previously. The animal presented initially with moderate pain signals, hemogram with discrepant results every 24 hours, and no occurrence of reduction of intestinal motility, hemorrhage, or peritonitis.

In the literature was not found any attempt to collect tissue to store for future cloning, as well as the maintenance of the ovaries that may allow ultrasound-guided ovarian aspiration (OPUS) for intracytoplasmic sperm injection.

\section{References}

[1] Slone DE. Ovariectomy, ovariohysterectomy, and cesarean section in mares. Vet Clin North Am Equine Pract 1988:4:451-9.
[2] Freeman DE, Rötting AK, Köllmann M, Doyle AJ, Troedsson MHT, Pozor M Lock T, Stewart A, Trumble T. Ovariohysterectomy in mares: 17 cases (1988-2007). In: Proceedings of the 53rd annual convention of the American Association of Equine Practitioners; 2007. p. 370-3.

[3] Kristina GL. Pyometra. In: McKinnon AO, Squires EL, Vaala WE, et al., editors. Equine reproduction. 2nd ed. Ames, IA: Blackwell Publishing; 2011. p. 2652-4.

[4] Santschi EM, Adams SB, Robertson JT, De Bowes RM, Mitten LA, Sojka JE. Ovariohysterectomy in six mares. Vet Surg 1995;24:165-71.

[5] Bartmann CP, Schiemann V, Poppe C, Schoon HA. Partille und radikale Hysterektomie beim Pferd. Tierärztl Prax 2003;31:6-15.

[6] Rötting AK, Freeman DE, Doyle AJ, Lock T, Sauberli D. Total and partial ovariohysterectomy in seven mares. Equine Vet J 2003;35:29-33.

[7] Asbury AC, Lyle SK. Infectious causes of infertility. In: McKinnon AO, Voss JL, editors. Equine reproduction. 6th ed. Ames, IA: Blackwell Publishing; 2005. p. 381-91.

[8] Hughes JP, Stabenfeldt GH, Kindahl H, Kennedy PC, Edqvist L-E, Neely DP, Schalm OW. Pyometra in the mare. J Reprod Fertil Suppl 1979:321-9.

[9] Van Camp SD. Breeding soundness examination of the mare and common genital abnormalities encountered. In: Morrow DA, editor. Current therapy in theriogenology. Philadelphia: W.B. Saunders Co.; 1986. p. 654-61.

[10] Causey RC. Making sense of equine uterine infections: the many faces of physical clearance. Vet J 2006;172:405-21.

11] Kennedy PC, Miller RB. The uterus. In: Jubb KVF, Kennedy PC, Palmer N, editors. Patholgy of domestic animals. 4th ed, vol. 3. San Diego: Academic Press, Inc; 1993. p. 372-87.

[12] Hughes JP, Loy RG, Asbury AC, Burd HE. The occurrence of Pseudomonas in the reproductive tract of mares and its effect on fertility. Cornell Vet 1966;56: 595-610.

[13] Brinsko SP. Chapter 1: reproductive anatomy of the mare. In: Brinsko SP, Blanchard TL, Varner DD, et al., editors. Manual of equine reproduction. 3rd ed. Maryland Heights, MO: Mosby Elsevier; 2011, p. 1-9.

[14] Sertich PL. Cervical problems of the mare. In: McKinnon AO, Voss JL, editors Equine reproduction. 6th ed. Ames, IA: Blackwell Publishing; 2005. p. 404-7.

[15] Prestes NC. Parto normal. In: Prestes NC, Landim-Alvarenga FC, editors. Obstetrícia veterinária. 2nd ed. Rio de Janeiro: Guanabara-Koogan; 2017. p. $69-80$.

[16] Sertich PL. Cervical adhesions, In: McKinnon AO, Squires EL, Vaala WE, et al. editors. Equine reproduction. 2nd ed. Ames, IA: Blackwell Publishing; 2011. p. $2721-3$.

[17] Tibary A. Failure to dilate. In: McKinnon AO, Squires EL, Vaala WE, et al., editors. Equine reproduction. 2nd ed. Ames, IA: Blackwell Publishing; 2011. p. $2724-30$.

[18] Threlfall WR, Carleton CL. Treatment of uterine infections in the mare. In Morrow DA, editor. Current therapy in theriogenology. Philadelphia: W.B. Saunders Co; 1986. p. 730-7.

[19] Brinsko SP, Blanchard TL, Varner DD, et al. Chapter 6: endometritis. In: Brinsko SP, Blanchard TL, Varner DD, et al., editors. Manual of equine reproduction. 3rd ed. Maryland Heights, MO: Mosby Elsevier; 2011. p. 73-84.

[20] Abou-Gabal M, Hogle RM, West JK. Pyometra in a mare caused by Candida rugosa. J Am Vet Med Assoc 1977;170:177-8.

[21] Roberts SJ. Veterinary obstetrics and genital diseases (theriogenology). 3rd ed. Woodstock: Stephen J. Roberts; 1986.

[22] Embertson RM. Uterus and ovaries. In: Auer JA, Stick JA, editors. Equine surgery. 4th ed. St Louis: Elsevier Saunders; 2012. p. 883-93. 